\title{
Impact of Compliance Programs on Organizational Psychology
}

\author{
Valeriu Deciu \\ University “Alexandru Ioan Cuza”, Iasi, Romania \\ Email: deciuvaleriu@gmail.com
}

How to cite this paper: Deciu, V. (2020). Impact of Compliance Programs on Organizational Psychology. Psychology, 11, 1862-1875.

https://doi.org/10.4236/psych.2020.1112118

Received: October 28, 2020

Accepted: December 18, 2020

Published: December 21, 2020

Copyright $\odot 2020$ by author(s) and Scientific Research Publishing Inc. This work is licensed under the Creative Commons Attribution International License (CC BY 4.0).

http://creativecommons.org/licenses/by/4.0/

(c) (i) Open Access

\begin{abstract}
An ethics and compliance program may impact employee role identity, hence influencing the psychology of the said organization. Ethics and compliance programs can be implemented differently by top managers. As stipulated, different orientations of compliance programs have different outcomes when it comes to employee responses. If an ethics and compliance program promotes a sense of shared responsibility and seems to suggest that it exists for the purpose of aiding employees to complete their tasks effectively, it can give the notion that the employees are supported by the organization. By promoting the idea of shared values within an organization, compliance, and ethical programs craft the expectations and norms within the said organization (Weaver \& Treviño, 1999: p. 319). According to theorists of social identity, it is these expectations that give employees a picture of the role they are expected to play within the organization. Apart from the role employees learn they are expected to play in an organization, interactions with others give them a sense of identity. Interactions with others within the organization as stipulated in ethics and compliance program do not just serve to point out what is expected of people within the organization, but also contributes to the sense of self employees have. Within organizations, values exist, most of which are centered around profit-making and the identity of people as profit-making managers. However, for an organization with a well-developed compliance program in place, there will be social interactions which will help define the expectation of each employee and will help them aspire to a set of common values throughout the organization (Weaver \& Treviño, 1999: p. 319). Therefore, the purpose of having shared values among the employees is to create role identities for employees within the organization. Compliance programs that take this approach aim at increasing salience of employees' ethical identities. In such an organization, even if one employee has a sense of self that values high commitment to ethics, a focus on the values of the organization will help increase salience (Weaver \& Treviño, 1999: p. 320).
\end{abstract}


Therefore, this proves that indeed ethics and compliance programs do have an influence on employee behavior, attitudes, values, and identities, hence influencing organizational psychology.

\section{Keywords}

Ethics, Compliance Programs, Identity, Organizational Behaviour

\section{Introduction (Review of Compliance Programs)}

When it comes to business compliance, the realities surrounding it can be overwhelming at times. Getting to fully comprehend all the applicable laws and regulations within an organization is a complex and time-consuming task. Corporate compliance programs are put in place within an organization to help people with the process (Deloitte, 2015). Corporate compliance programs are basically the set of internal policies and procedures applied by an organization to ensure that it complies with laws and regulations of the country while also upholding its reputation to its customers. Such programs are integral to organizations, and it is not uncommon for multinational organizations to spend millions on compliance. There are certain factors that make an organization's compliance programs better performing than those of others (Deloitte, 2015). According to Deloitte, an excellent compliance program has five key elements.

\section{Elements of Effective Compliance Programs}

\subsection{Tone at the Top}

The first element is the tone at the top. The top managers and officials set the tone for an organization. They should not just focus on giving instructions and providing verbal guidance to their subordinates. To ensure a compliance program is effective, top managers need to invest resources and time to educate themselves that others on the importance of these compliance programs and how they would benefit the organization (Deloitte, 2015). Furthermore, they should ensure that those in charge of dealing with such programs have enough resources to make their work easier.

\subsection{Corporate Culture}

The second factor that plays a huge role in determining how effective a compliance program is within an organization is its corporate culture (Deloitte, 2015). A corporate culture built on integral goes a long way in ensuring compliance programs are effective. If an organization's culture is built around integrity, it is impossible for the employees to develop a negative attitude towards compliance programs. However, for one, without such a culture, compliance programs may be viewed as restrictive and may not be as effective (Deloitte, 2015). 


\subsection{Risk Assessment}

The risk assessment also determines how compliance programs turn out in organizations. It is imperative to look at the risks facing an organization while looking at the organization as a whole. It is through such assessments that top managers can determine the most significant risks and identify how they can be mitigated (Deloitte, 2015). Risk identification is what provides the basis for the kind of actions an organization needs to take. It is also critical to have a person in charge of overseeing such compliance programs. The individual will be tasked with ensuring compliance is observed and identifying potential risks to an organization's reputation and how they can be mitigated (Deloitte, 2015). Having a skilled head will allow organizations to have effective compliance programs.

A compliance program can be effective for a long time if testing and monitoring are observed. The process starts with putting control measures in place and testing them regularly to ensure that they are still effective (Deloitte, 2015). Most organizations, particularly highly regulated industries like the healthcare industry, spend millions of dollars annually to ensure their compliance programs are effective. The purpose of compliance programs is to ensure that organizations eliminate ethical failures and the legal processes that come with such (Deloitte, 2015). Most organizations may have the misconception that compliance programs in place automatically change the performance and behavior of their employee. Companies strive to make their compliance programs as effective as possible to ensure ethical behavior is observed (Deloitte, 2015). Compliance programs have a huge impact on organizational psychology as they influence employee identity, values, perception of the organization, and if properly implemented, compliance programs define the expectation of an organization, thus changing people's perception of their roles.

\section{Nature of Compliance Programs}

Compliance programs change from one company to another, depending on the industry it operates within. The nature of training and codes that come with compliance programs are different for organizations. It is critical for managers to understand that the design of programs affects compliance within organizations (Busse and Doganer, 2018: p. 335). Most existing corporate organizations do not always abide by the laws of the nation they operate in, as evidenced by the numerous shameful scandals witnessed in even multinational organizations. Organizations like Siemens have been caught bribing officials, and others like Wal-Mart have been caught bribing officials to expand their operations (Busse and Doganer, 2018: p. 335). The two organizations are not the only ones involved in scandals; the list of the companies involved in such scandals is endless, stressing the need for compliance. Organizations in the US with compliance programs continue to increase, with the aim of curbing corruption and misconduct in organizations as corruption continues to be a concern in many organiza- 
tions. The introduction of compliance programs changes the operations of many organizations (Busse and Doganer, 2018: p. 335). It also changes the employees' perception of ethical regulations and laws (Busse and Doganer, 2018: p. 336). Within an organization, there is no doubt that establishing codes and ensuring employees are committed to them is a major form of organizational change.

\subsection{Compliance Programs in Organizations}

Compliance programs involve training and codes, which change employees' behaviors and understanding of the law. However, there is no doubt that employees could react negatively to changes, as this often happens during major organizational changes (Kral, 2020). They may perceive a change in their work and routines as too risky. Since compliance programs are aimed at influencing change, they may face similar issues (Kral, 2020). Managers should, therefore, take into consideration these challenges as they plan to put such programs. Small and medium businesses are perhaps the least prepared in such situations as they tend to underestimate compliance issues and can be unprepared in such situations (Kral, 2020). Scandals in organizations like Wells Fargo come even after such organizations spend millions of dollars on compliance issues. Organizations spend resources on training programs, hotlines, and other systems meant to deal with the violation of laws. In organizations that are heavily regulated like accounting firms, the money spent on such regulations can be up to hundreds of millions of dollars (Kral, 2020). However, these costs do not always factor in every cost as employees lose hundreds of hours in training. Organizations risk spending thousands on compliance without yielding any substantial results, making it critical to ensure compliance programs are efficient (Kral, 2020). It becomes important for organizations to ensure they question whether these programs put in place serve to waste resources, or they are indeed helpful to the organization. In most cases, it boils down to the organizational culture and understanding of how to best improve regulatory programs (Chen and Soltas, 2018). Organizations should look beyond the organizational walls to fully understand how to best deal with compliance issues. This involves looking at industry-wide developments and assessing how competitors react to certain issues. It is also critical for organizations to ensure that every employee understands his or her role in implementing the compliance program. It is also critical to define the reason behind the compliance programs to ensure that the employees understand (Chen and Soltas, 2018). It is also important for heads of organizations to look at the feedback of the employees after they are educated. A corporate compliance program is essential in avoiding scandals, making it instrumental in protecting an organization's reputation (Chen and Soltas, 2018). It is hence essential for organizations to ensure their compliance programs are efficient.

\subsection{Compliance Programs on Employee Behavior}

As previously stated, the orientation of ethics and compliance programs vary in 
nature and orientation. The US Sentencing Commission has put pressure on organizations to have such programs in place. According to the body, organizations that do not have such programs in place face the risk of being heavily fined in case they engage in fraudulent or illegal activities (Weaver \& Treviño, 1999: p. 315). Many organizations in the US put in place these programs to comply with the government's directives. However, others already had these programs in place prior to the sentencing guidelines were put in place. Looking at the history of compliance programs, it becomes evident that ethics and compliance programs tend to stress values, responsibility, and accountability among employees of organizations. According to Paine (1994), programs that stress responsibility, guidance, and counseling tend to be more effective than those that stress rule compliance (Weaver \& Treviño, 1999: p. 315). Rule compliance programs are, in most cases, heavily influenced by how well the executives are familiar with the guidelines of the United States Sentencing Commission as well as the management's commitment to ethical conduct within the organization (Weaver \& Treviño, 1999: p. 315). A survey-based study by Trevino, Weaver, Gibson, and Toffler revealed that most compliance programs are likely to be created to satisfy the expectation of external stakeholders. According to them, such programs are likely to only serve the purpose of protecting the reputation of top managers in case of a scandal rather than complying with the law or ensuring organizational operations are ethical. Regardless of the type of orientation put in place, it is important to note that the purpose of such programs is usually to bring some degree of predictability within an organization, and most importantly, to bring order (Weaver \& Treviño, 1999: p. 316). These ethics programs are basically controlled programs within organizations. Their purpose is to ensure employee behavior is predictable, and their behavior corresponds to certain organizational goals.

\subsection{Compliance Programs and Organizational Culture}

Control and compliance programs continue to attract the attention of scholars analyzing the impacts of the same on organizational psychology and culture. Contol and compliance programs possess many dimensions, and analysis can be performed from any of the dimensions (Weaver \& Treviño, 1999: p. 315). While these programs are known for their ability to bring order within an organization, it is important to question whether they bring order by enforcing behavioral compliance or by ensuring employees identify with and stay committed to organizational values. Compliance programs are often viewed as necessary to ensure employee behavior conforms with what the organization requires (Weaver \& Treviño, 1999: p. 317). This is, at times, done coercively. However, organizations can also choose to bring conformity by ensuring their employees identify with their goals and values and identify with them. For the former to work, organizations also need to ensure they are familiar with the goals and needs of their employees for it to work (Weaver \& Treviño, 1999: p. 317). The two can be judged by how compliance programs are enforced, and the approach managers use to 
get the attention of their employees (Weaver \& Treviño, 1999: p. 317). Compliance programs typically focus on punishment when rules are not observed. Such programs are focused on rule compliance solely, and non-compliance leads to punishment. Ethical programs, on the other hand, focus on ensuring employees are committed to an organization's ethical ideologies and that their values embody those of the organization in question (Weaver \& Treviño, 1999: p. $317)$. In that sense, one is focused on value orientation and the other on compliance orientation. An example of a compliance orientated program is a construction company having its ethical conduct phrased in terms of legal compliance (Weaver \& Treviño, 1999: p. 317). In such a case, the compliance program involved an attorney, and the employees are likely to be taught the rules they are required to comply with, and such an organization is likely to also stress the consequences of not complying with these regulations. In contrast, an ethics program in a healthcare facility is likely to involve the Human Resources manager, the marketing department, and the operations department (Weaver \& Treviño, 1999: p. 318). It is likely to involve the promotion of values like responsibility, respect, and integrity. Such programs may not focus on promoting stipulated ideals with punishment. Rather, such a program will simply promote the ideals to the employees and highlight how the ideals are likely to benefit the organization and the employees (Weaver \& Treviño, 1999: p. 318). The ideals can be articulated and affirmed by the organizational leaders formally or informally. The type of orientation employed by an organization, therefore, will have an impact on the psychology of the organization in question.

\section{Using the Organizational Psychology}

Organizational or occupational psychology is a field of psychology that looks at the behavior of human beings within an organization zeroing in on why people like or dislike their jobs. The field focuses on deriving the organizational, individual, and departmental principles and assessing how this knowledge can be instrumental in providing a solution to an organizational problem (O'Connel, 2020). Organizational psychology revolves around gaining knowledge on the behavior of employees and the organization at large. The understanding and knowledge require an in-depth understanding of the organization's development, human factors, human resources, and decision theory. Compliance programs have been shown to have an impact on the behavior of the stakeholders of an organization, depending on the approach embraced by the top managers (O'Connel, 2020). Compliance programs, according to Pain, are effective in generating conformity from employees. However, she points out that they do very little to generate a commitment to organizational values. She believes that this happens because compliance programs are associated with the minimalist attitude, where employees are focused on not getting caught rather than conforming to the values of the organization (Weaver \& Treviño, 1999: p. 318). How do compliance programs affect the ethics of organizations? How do they influence the employee's 
views of the organization? It is critical to look at how compliance programs change organizational psychology by assessing the behavior of the stakeholders. Since compliance programs encompass everything from whistleblowing systems to established codes of conduct for the employees, there is no doubt that they impact organizational psychology to a great extent (Weaver \& Treviño, 1999: p. 318). Compliance programs involve behavioral controls to ensure that the values of the organization are in sync with employee behavior. Corporate compliance programs and systems have the potential to change and influence employee behavior within an organization, hence affecting organizational psychology as a whole (Weaver \& Treviño, 1999: p. 319). It makes sense to stipulate that the key functions of compliance programs are to identify non-compliance, correct it, and to prevent a recurrence of the same within the organization (Weaver \& Treviño, 1999: p. 319). This, however, is only true for properly designed programs (Parker \& Nielsen, 2008: p. 3). Such programs influence organizational behavior positively, while ineffective programs can have adverse implications when it comes to organizational psychology.

\subsection{Organizational Psychology, Culture, and Compliance Programs}

There is definitely more research on how organizational culture affects the performance of compliance programs than there is on how compliance programs impact organizational culture and behavior. It is obvious that those organizations with organizational cultures that encourage compliance are more likely to have effective compliance programs. Programs are believed to influence organizational practices positively. However, since change is only possible if the employees are willing to accept the change, it is important to assess how the various types impact behavior to identify the kind of compliance programs that have a positive impact on employee psychology. A 2002 study by Simpson assessed the factors that affect employees' intentions to commit a crime within an organization (Parker \& Nielsen, 2008: p. 5). She used a sample of MBA students and managers in her study. Her study indicated that the variables that measure authority structures and internal compliance were shown to have more impact on decision making when it comes to corporate crimes than any other existing variables (Parker \& Nielsen, 2008: p. 5). The other variables she looked at include legal sanctions, pressure, and firm benefits. Furthermore, data from the study indicated that the structure of compliance programs did not have as much impact on the conduct of employees as the operation. Looking at how compliance programs impact the observance of regulations and laws, Potoski and Prakash in their 2005 study indicated that voluntary implementation of compliance programs do lead to better environmental compliance and the observance of clean air regulations (Parker \& Nielsen, 2008: p. 6). This study vindicates the findings of a 2000 study by Dasgupta, Hettige, and Wheeler that stipulated that organizations with compliance programs in place have superior environmental com- 
pliance. Another study by Kagan, Gunningham, and Thornton conducted in 2003 showed that managers' attitudes towards environmental issues could be impacted positively by compliance programs. The study indicated that cush programs encouraged compliance or over-compliance to regulations within organizations (Parker \& Nielsen, 2008: p. 6). The implementation of compliance programs has an impact on how managers manage various activities throughout the organization and the decisions made to encourage actual compliance (Parker \& Nielsen, 2008: p. 6). Therefore, compliance programs do have an influence on organizational compliance by influencing compliance management in practice by influencing the decisions made by management.

\subsection{Compliance Programs in Organizations}

Compliance programs involve training and codes, which change employees' behaviors and understanding of the law. However, there is no doubt that employees could react negatively to changes, as this often happens during major organizational changes (Kral, 2020). They may perceive a change in their work and routines as too risky. Since compliance programs are aimed at influencing change, they may face similar issues (Kral, 2020). Managers should, therefore, take into consideration these challenges as they plan to put such programs. Small and medium businesses are perhaps the least prepared in such situations as they tend to underestimate compliance issues and can be unprepared in such situations (Kral, 2020). Scandals in organizations like Wells Fargo come even after such organizations spend millions of dollars on compliance issues. Organizations spend resources on training programs, hotlines, and other systems meant to deal with the violation of laws. In organizations that are heavily regulated like accounting firms, the money spent on such regulations can be up to hundreds of millions of dollars (Kral, 2020). However, these costs do not always factor in every cost as employees lose hundreds of hours in training. Organizations risk spending thousands on compliance without yielding any substantial results, making it critical to ensure compliance programs are efficient (Kral, 2020). It becomes important for organizations to ensure they question whether these programs put in place serve to waste resources, or they are indeed helpful to the organization. In most cases, it boils down to the organizational culture and understanding of how to best improve regulatory programs (Chen and Soltas, 2018). Organizations should look beyond the organizational walls to fully understand how to best deal with compliance issues. This involves looking at industry-wide developments and assessing how competitors react to certain issues. It is also critical for organizations to ensure that every employee understands his or her role in implementing the compliance program. It is also critical to define the reason behind the compliance programs to ensure that the employees understand (Chen and Soltas, 2018). It is also important for heads of organizations to look at the feedback of the employees after they are educated. A corporate compliance program is essential in avoiding scandals, making it instrumental in pro- 
tecting an organization's reputation (Chen and Soltas, 2018). It is hence essential for organizations to ensure their compliance programs are efficient.

\section{Corporate Compliance on Organizational Psychology}

Compliance practitioners and regulators may invoke the whole idea of the corporate culture to argue that it is the concept of compliance culture that influences compliance, not compliance programs. However, Hoogervorst, van der Flier, \& Koopman, in their 2004 paper, argue that the concept of corporate culture is in itself a multifaceted concept (Parker \& Nielsen, 2008: p. 7). Organizational culture is usually used to refer to the shared beliefs, interpretations, and meanings within an organization (Parker \& Nielsen, 2008: p. 7). It can also be used to refer to the implementation of corporate compliance programs and practices within an organization. Therefore, compliance culture can be used to mean that organizations are not only required to have compliance systems and programs, but they should also ensure that the compliance systems and programs in place are implemented in the organization's everyday practices (Parker \& Nielsen, 2008: p. 8). Valerie Braithwaite, in a 2003 study, shows that people's values and motivational postures toward compliance with regulators tend to be distinct with their behaviors and compliance actions (Parker \& Nielsen, 2008: p. 8). This is to say, within an organization, the behavior of people may not be a reflection of their attitudes and beliefs toward an established regulator. She stipulates that the actions of people within an organization are subject to situational factors such as the barriers, opportunities, and habits (Parker \& Nielsen, 2008: p. 8). When it comes to organizational situations and compliance programs, values that support compliance within an organization are likely to have an impact on people's behavior towards compliance. The everyday actions of people within an organization is likely to be subject to the extent to which formal programs that deal with compliance (Parker \& Nielsen, 2008: p. 9). A compliance program that puts emphasis on compliance and stresses individual responsibility of compliance is likely to have a positive impact on people's behavior towards compliance (Parker \& Nielsen, 2008: p. 9). This is to say that compliance management programs within an organization are essential to ensure people comply with set regulations (Parker \& Nielsen, 2008: p. 9). Since employee behavior is largely influenced by existing factors within an organization, it is essential for top managers to ensure they have measures in place that encourage compliance.

\subsection{Organizational Support, Compliance Programs, and Organizational Psychology}

Compliance and ethics programs can be tailored in a manner that gives the notion of organizational support to the employees and value orientation, resulting in a change in employee behavior. According to the theory of social exchange, when an individual receives some form of social benefit from another, a reciprocal expectation for a return favor is automatically created (Cropanzano, An- 
thony, Daniels, \& Hall, 2017: p. 479). The theory suggests that resources are, in many cases, exchanged through the process of reciprocity. In this case, one individual will receive a resource and is likely to want to repay the good deeds of an individual with a similarly good deed. The quality of exchanges largely depends on the kind of relationship two people share (Cropanzano, Anthony, Daniels, \& Hall, 2017: p. 480). The social exchange theory has been the subject of many resources, with people looking at the exchange of resources between subordinates and superiors as well as the exchange between organizations and its members. Recently, studies have looked at the influence of organizational support as a form of social benefit exchange. How do employees perceive support from their employers? Employers can create the notion of support through articulating their appreciation for the contributions of their employees and taking actions that show they care for their employees (Weaver \& Treviño, 1999: p. 320). These actions are likely to create a sense of obligation among the employees, who may feel obligated to reciprocate the social benefit (Cropanzano, Anthony, Daniels, \& Hall, 2017: p. 480). Organizational support has, therefore, been associated with positive employee response and commitment to organizational goals and objectives. Compliance and ethic programs that place importance on values may be viewed as supporting employees. Instead of such compliance programs revolving around detection and discipline for offenses committed, they can be focused on promoting values. Programs focused on discipline and detection of non-compliance seem to communicate that the employees cannot be trusted (Weaver \& Treviño, 1999: p. 320). According to the social exchange theory, employees may reciprocate by committing offenses and hiding them as long as they do not get caught as such a program communicates distrust. A program centered on promoting values acknowledges that employees are already committed to ethical behavior (Weaver \& Treviño, 1999: p. 320). The program focuses on the development of shared values and the perceived support of employees. The emphasis is, in most cases, on activities that seem to support the employee decision-making process (Weaver \& Treviño, 1999: p. 320). Such a compliance program promotes counseling to employees on how they can adhere to the established guidelines for their own good and that of the organization (Weaver \& Treviño, 1999: p. 320). It supports the aspirations of the employees and gives them the notion that the organization embodies commitments that apply to all the stakeholders equally (Weaver \& Treviño, 1999: p. 320). Therefore, compliance programs promote a sense of obligation in employees if they are value-oriented as they create a sense of perceived organizational support, which in turn makes the employees feel obligated to perform better and to comply with the regulations.

\subsection{Negative Psychological Impacts of Compliance Programs}

Compliance programs that look at compliance rather than values of employees are more likely to be oriented towards behavioral monitoring and punishment for no-compliance. Such programs do not look at the needs of the employees or 
suggest support for them in any way. If anything, they look at employees as unethical and cannot be trusted (Weaver \& Treviño, 1999: p. 323). On the other hand, punishing employees for misconduct or non-compliance may suggest that the organization values certain standards of justice and may suggest that it also values its employees. Without other indicators of support and value from the head of the organization, employees may simply look at the punishing as something that should be feared and avoided at all costs. In many cases, how employees view punishment is dependent on the surroundings of the punishment, encompassing factors like the kind of relationship the employee shares with the person doing the punishing and the fairness with which the punisher carries out the punishing. Compliance programs that pay more attention to disciplining and punishing non-compliance are likely to engender a contractual attitude from the employee towards the organization, instead of support and trust (Weaver \& Treviño, 1999: p. 323). Although such a program is likely to result in compliance on the part of the employees, the compliance may simply revolve around calculation and conditioning rather than focusing on role definition. It works best in situations where the employee is threatened by punishment or more severe consequences for non-compliance (Weaver \& Treviño, 1999: p. 323). Such rules, as stipulated earlier on, do not define the expectations of the top managers and the organizations in general when it comes to the employees performing their duties. These rules, in most cases, seem to be originating from the outside and do not factor in the values of the employees and their culture within the organization. They constitute a top-down approach rather than focusing on integration (Weaver \& Treviño, 1999: p. 323). The salience created by this approach usually results from the fear of the employees. Moreover, the constant monitoring propagated by this kind of approach communicates distrust. When distrust and fear are combined, they may breed a calculative self-interest response to the program put in place. In this case, the compliance program is not likely to result in organizational commitment (Weaver \& Treviño, 1999: p. 323). However, their outcomes are not all bad. The fear of punishment due to non-conformity can have a hand in reducing the number of unethical behaviors and cases of non-compliance within the organization. Such a program also encourages employees to ensure they are familiar with all the rules of the organization to avoid being punished (Weaver \& Treviño, 1999: p. 323). It also encourages employees to seek advice from their superiors to avoid the disciplinary actions that come with non-compliance without seeking advice (Weaver \& Treviño, 1999: p. 323). Therefore, compliance programs centered around discipline and compliance are not likely to breed commitment to the organization. However, they encourage employees to avoid non-compliance, hence reducing the number of incidents that involve unethical behavior within the organization.

\subsection{Compliance Programs and Organizational Psychology}

Some critics argue that compliance programs only serve to police the boundaries 
of non-compliance within the organizations, particularly internal compliance programs. This means that such programs do not encourage employees to avoid non-compliance as part of the organizational values (Parker \& Nielsen, 2008: p. 10). Rather, such compliance programs only encourage employees to adopt the mentality of the bare minimum. Many internal non-compliance programs serve to eliminate the risk of non-compliance that will be costly to the organization only. In such a situation, the top managers focus their attention on setting boundaries in a manner that allows some risk of non-compliance but does not eliminate it altogether (Parker \& Nielsen, 2008: p. 10). Such a view of compliance programs gives the notion that the management does not value compliance but only does so to appease the regulator. The employees may adopt a similar view and may only invest in doing very little to benefit the organization. Less than perfect compliance programs within an organization may have negative implications on employee behavior and their perception of right and wrong. Such programs may end up giving the employees a flawed view of what is expected of them (Parker \& Nielsen, 2008: p. 28). This assessment of the implementation of compliance programs confirms the arguments of scholars on the same. Critics argue that the implementation of compliance programs that do not also stress values may not be as effective. For programs to be effective, they need to connect to the organizational culture (Parker \& Nielsen, 2008: p. 28). A study carried out by Parker and Nielsen in 2008 on compliance programs indicated that the implementation of formal compliance programs affected the organizational culture and influences how organizations view compliance in practice. Apart from that, they discovered that good management and good organizational culture affect how effective compliance programs are implemented in practice and their effectiveness in an organization (Parker \& Nielsen, 2008: p. 28). They also observe that larger organizations are more likely to implement these programs with ease than small organizations. They were also found to have higher levels of values, a factor the researchers believe played a huge role in making it easier for them to implement these programs (Parker \& Nielsen, 2008: p. 28). Therefore, compliance programs can be effective if an organization chooses to emphasize on both values and compliance to make the management of such a program easier.

\subsection{Formal Compliance Programs}

It is evident that the implementation of formal compliance programs is not associated with the desired psychological impacts on the organization. It is necessary for the compliance programs to support and promote the organization's culture of compliance. Compliance management in practice is used to refer to how managers and employees of an organization respond to compliance issues within the organization (Parker \& Nielsen, 2008: p. 28). Compliance programs are meant to help improve compliance within an organization by influencing compliance management. Without an emphasis on values, compliance programs 
are but a waste of time and resources, which achieves only a portion of what good management can achieve. It becomes evident that it is a combination of factors that make a good compliance program (Parker \& Nielsen, 2008: p. 28). Employees can actively accept compliance programs or reject it. It is important for managers to keep in mind that although codes are, in most cases, the central element in compliance programs, they are not always enough to inspire a change of behavior from the employees (Parker \& Nielsen, 2008: p. 28). Codes may actually fuel rebellion from employees, or they may adopt a negative view of the organization and the management. It is important to place emphasis on training programs to ensure people within an organization are familiar with the established codes (Stöber, Kotzian, \& Weißenberger, 2018). It is highly unlikely that the mere existence of codes will affect the behavior of people within an organization if the compliance program is not effective and comprehensive. Compliance training focuses on making clear the purpose of the code, how it will affect people's tasks, and the consequences of ignoring them. Training allows people to develop a view of the program and whether or not they consider it acceptable. The whole point of organizations having programs in place is to ensure the risk of non-compliance is minimized. How such is implemented is what influences organizational psychology (Stöber, Kotzian, \& Weißenberger, 2018). Organizational managers can also be impacted by such programs once they are put in place. Since they are the ones tasked with implementing such, their behavior and view of other employees can change as well (Stöber, Kotzian, \& Weißenberger, 2018). Compliance programs are necessary for organizations to function. However, it is important to have proper training in place to minimize the negative psychological impact they can have on the organization as a whole.

\section{Conclusion}

Compliance programs and their orientations have a significant role to play in transforming organizational psychology. As evidenced by exchange theory and perceived exchange theory, compliance programs have the power to transform how employees view their roles, identity, and the organization as a whole. Generally, compliance programs are associated with a number of outcomes when it comes to employee behavior, including ethical awareness, and decreased level of unethical behaviors within an organization. Furthermore, if designed properly, a compliance program encourages employees to report unethical behavior and to avoid such behaviors. Good values and good management also play a role in how effective a compliance program is in an organization. However, compliance programs can also encourage employees to be calculative and technical. In some cases, compliance programs focus on compliance and disciplining non-compliance. In such cases, employees may avoid non-compliance due to the fear of being punished, not because they are committed to an organization. In a way, this can be a good thing as it ensures non-compliance is limited. When it comes to programs that factor in values, employees are more likely to be receptive to these 
and to identify with them. Such programs encourage hard work, commitments, and ethical behavior by connecting with employees. It is, however, evident that whatever the approach adopted, compliance programs impact organizational psychology.

\section{Conflicts of Interest}

The author declares no conflicts of interest regarding the publication of this paper.

\section{References}

Busse, R., \& Doganer, U. (2018). The Role of Compliance for Organisational Change. Journal of Organizational Change Management, 31, 334-351. https://doi.org/10.1108/JOCM-05-2017-0163

Chen, H., \& Soltas, E. (2018). Why Your Compliance Programs Are a Million-Dollar Waste of Time.

https://hbr.org/2018/03/why-compliance-programs-fail

Cropanzano, R., Anthony, E. L., Daniels, S. R., \& Hall, A. V. (2017). Social Exchange Theory: A Critical Review with Theoretical Remedies. Academy of Management Annals, 11, 479-516. https://doi.org/10.5465/annals.2015.0099

Deloitte (2015). Building World-Class Ethics and Compliance Programs: Making a Good Program Great Five Ingredients for Your Program.

https://www2.deloitte.com/content/dam/Deloitte/no/Documents/risk/Building-worldclass-ethics-and-compli-ance-programs.pdf

Kral, R. (2020). Effective Corporate Compliance Programs. https://www.corporatecomplianceinsights.com/effective-corporate-compliance-progra ms-ron-kral-candela

O’Connel, A. (2020). It's Time to Question Everything about Best-Practice Compliance. https://www.ethicalsystems.org/its-time-to-question-everything-about-best-practice-co mpliance/

Paine, L. S. (1994). Managing for Organizational Integrity. Harvard Business Review, 17-106.

Parker, C., \& Nielsen, V. L. (2008). Corporate Compliance Systems. Administration \& Society, 41, 3-37. https://doi.org/10.1177/0095399708328869

Stöber, T., Kotzian, P., \& Weißenberger, B. E. (2018). Design Matters: On the Impact of Compliance Program Design on Corporate Ethics. Business Research, 12, 383-424. https://doi.org/10.1007/s40685-018-0075-1

Weaver, G. R., \& Treviño, L. K. (1999). Compliance and Values Oriented Ethics Programs: Influences on Employees' Attitudes and Behavior. Business Ethics Quarterly, 9, 315-335. https://doi.org/10.2307/3857477 